\title{
Correction to: Financial Development-Economic Growth Nexus: Theoretical Underpinnings, Empirical Evidence, and Critical Reflections
}

\author{
Ahmed Imran Hunjra, Murugesh Arunachalam, and Mahnoor Hanif
}

\section{Correction to:}

Chapter 9 in: M. Shahbaz et al. (eds.), Economic Growth and Financial Development, https://doi.org/10.1007/978-3-030-79003-5_9

The book was inadvertently published with a typo in affiliation of Prof. Ahmed Imran Hunjra title from chapter 9 'Financial Development-Economic Growth Nexus: Theoretical Underpinnings, Empirical Evidence, and Critical Reflections'. The city name was corrected to 'Dera' from 'Dear'. 